\title{
Towards a Phenomenology of Self-Patterns in Psychopathological Diagnosis and Therapy
}

\author{
Anya Daly ${ }^{a}$ Shaun Gallagher ${ }^{b}$ \\ ${ }^{a}$ School of Philosophical and Historical Studies, The University of Melbourne, Melbourne, VIC, Australia; ${ }^{b}$ Lillian and \\ Morrie Moss Chair of Excellence in Philosophy, Department of Philosophy, University of Memphis, Memphis, TN, USA
}

\section{Keywords}

Psychiatric diagnosis - Pattern theory of self .

Psychopathology · Phenomenological interview ·

Narrative · Therapy

\begin{abstract}
Categorization-based diagnosis, which endeavors to be consistent with the third-person, objective measures of science, is not always adequate with respect to problems concerning diagnostic accuracy, demarcation problems when there are comorbidities, well-documented problems of symptom amplification, and complications of stigmatization and looping effects. While psychiatric categories have proved useful and convenient for clinicians in identifying a recognizable constellation of symptoms typical for a particular disorder for the purposes of communication and eligibility for treatment regimes, the reification of these categories has without doubt had negative consequences for the patient and also for the general understanding of psychiatric disorders. We argue that a complementary, integrated framework that focuses on descriptive symptom-based classifications (drawing on phenomenological interview methods and narrative) combined with a more comprehensive conception of the human subject (found in the pattern theory of self), can not only offer a solution to some of the vexed issues of psychiatric diagnosis but also support more efficacious therapeutic interventions.
\end{abstract}

(c) 2019 The Author(s)

Published by S. Karger AG, Basel

\section{KARGER}

E-Mail karger@karger.com www.karger.com/psp
(C) 2019 The Author(s)

Published by S. Karger AG, Basel

Karger

Open access

This article is licensed under the Creative Commons AttributionNonCommercial-NoDerivatives 4.0 International License (CC BY NC-ND) (http://www.karger.com/Services/OpenAccessLicense). Usage and distribution for commercial purposes as well as any distribution of modified material requires written permission.

\section{Introduction}

"What is Dr. Monro? A mad-doctor; and pray what great matter is that? What can mad-doctors do? Prescribe purging, physic, letting of blood, a vomit, cold bath, and a regular diet? How many incurables are there?... physicians .... are often poor helps; and if they mistake the distemper, which is not seldom the case, they do real mischief."

Alexander Crudden, The Adventures of Alexander the Corrector, London 1754 [1].

The history of psychiatry has been one of successive theories, diagnostic methods, and treatments, each enthusiastically welcomed as having the potential to solve mysteries and resolve mental distress, and each eventually found inadequate to the task to greater or lesser extents - from humoral theory, to confinement, to the moral treatments of the 18th and 19th centuries, to the medical model, to psychoanalysis, to behaviorism, to psychosurgical interventions, to the social constructionist theories originating in the 1960s [2-4], to psychopharmacology, to psychogenetics, and more recently to the neurobiological and hybrid biopsychosocial models [46]. The historical treatments of the "mad," justified on the basis of various diagnostic categorizations, have ranged from the benign and sometimes helpful, to the ludicrous, to the most brutal, criminally reprehensible, and politically oppressive [7].

Dr. Anya Daly

PO Box 4111 University of Melbourne

Parkville, Melbourne, VIC 3052 (Australia)

E-Mail amdaly@unimelb.edu.au, anyadaly008@gmail.com 
Even today when the important historical revelations from dissenters and critics are more readily accessible, there remain issues of serious concern that need to be addressed [8-16]. These are concerns regularly raised by psychiatrists themselves and not only by critics and conspiracy theorists who tend to overlook the cases of those who have benefitted from psychiatric care. Many psychiatrists freely admit and expose the limitations of aspects of the various current psychiatric models in their struggle to adapt them to better serve the interests of those under their care [17-30].

Pressures from the wider society, from the medical establishment and from within psychiatry itself to justify psychiatric practice according to the measures and standards of medicine, we propose, have not only contributed to psychiatry's crisis of legitimacy but have also distorted understandings of the psychiatric subject, thereby undermining the efficacy of psychiatric practice from diagnosis through to treatment. Unlike medical practice which can call on blood tests, scans and physical examinations to determine the cause of ill-health, to reduce the possibility of misdiagnosis, and to evaluate cases where there may be symptom amplification, psychiatry's means and measures have been much more uncertain. While there is reason to hope that genetics and neuroscience are going to deliver the kinds of hard-science certainties previously only the occasional privilege of physical medicine, in our view, there will still remain much that goes beyond genes, neural activation and brain scans. ${ }^{1}$ Furthermore, even if the findings were able to establish clear correlations between genes, neural states and mental illness, what remains to be understood in every case will be the subjective experience of the person under consideration - what it is like to have such states and how these states impact on the various aspects of a patient's life. In this paper, we want to pursue a thought that has been around at least since the time of Jaspers [32, 33], namely, that naturalistic explanations of mental illness relying on neurochemistry, neuroimaging and neurobiology, that is, third person accounts, need to be brought into a more rigorous engagement with first person phenomenological accounts to optimally capture the sometimes anomalous experience of those living through psychiatric disorders. ${ }^{2}$

Phenomenologist and psychiatrist Karl Jaspers, wary of the common tendency to reify categories and classifica-

\footnotetext{
${ }^{1}$ Thomas Insel, for example, writes: "I spent 13 years at NIMH really pushing on the neuroscience and genetics of mental disorders, and when I look back on that I realize that while I think I succeeded at getting lots of really cool papers published by cool scientists at fairly large costs - I think $\$ 20$ billion - I don't think we moved the needle in reducing suicide, reducing hospitalizations, improving recovery for the tens of millions of people who have mental illness. I hold myself accountable for that" [29].
}

tions, noted long ago, "classification has only a provisional value. It is a fiction which will discharge its function if it proves to be the most apt for the time" $[32,33]$. In this paper, we take up some of Jasper's insights and integrate these into a new approach. As an alternative to medicalized classificatory systems such as the DSM, we present the case for using the Pattern Theory of Self (PTS) combined with phenomenological methods of interview, which, we argue, do justice to the phenomena and the lived experience of those suffering anomalous experiences. This approach, based on enactive (embodied, embedded, and phenomenological) conceptions, addresses issues such as the pitfalls of possible misdiagnosis associated with fixed diagnostic categories, and the dehumanizing effects of the structured diagnostic checklist, through the use of a "rich diagnosis" centered on the multi-dimensionality of lived experience. Furthermore, this approach returns a significant measure of epistemic responsibility to the individual suffering disordered or anomalous experiences.

In brief, the alternative we are proposing avoids biological or neurological reductionism as well as the denial of subjective psychological distress found in extreme versions of social constructionism. How then do we proceed? While diagnostic categories may serve a useful purpose by fulfilling the role of a "field guide" 3 as a first basis for a working identification, we will argue that an integrated framework that focuses on descriptive symptombased classifications (based on phenomenological interview methods) combined with a more comprehensive conception of the human subject (found in PTS), which incorporates both phenomenology and the cognitive sciences, will offer a solution to the well-documented problems of psychiatric diagnosis and treatment.

\footnotetext{
${ }^{2}$ See Thomas Fuchs' recent book Ecology of the Brain, for a thoroughgoing analysis of the origins and deficiencies of neurocentric reductionism and how this is impacting on psychiatric theory and practice. The key insight he promotes is that "the brain is an organ of a living being, not of the mind" (p.v) [31]. The account we are advancing also coheres well with that proposed by psychiatrists Matthew Broome and Giovanni Stanghellini in their paper "Psychopathology as the Basic Science of Psychiatry" [26]. They also recognize that through the efforts to legitimate psychiatry the "object/subject of psychiatry" has been lost both to the detriment of the profession and most certainly to the detriment of the patient suffering mental health issues. See also Sass and Parnas [34]; Colombetti [35].

3 Thanks to Nick Haslam (University of Melbourne) for suggesting this analogy. Indeed, this is the way that diagnostic categories function even in phenomenological psychiatry. As one reviewer noted, phenomenological psychiatry focuses on certain psychopathological Gestalts (schizophrenia, melancholia, etc.), which can be viewed as categories in some sense of the term. Such Gestalts entail prototypical cases at the center of the category with a diminishing typicality toward the boundaries of the category where it may overlap other categories. Our proposal is not to eliminate these psychopathological Gestalts but to situate their clinically informed use in a broader and more comprehensive conception of the human subject.
}

Daly/Gallagher 


\section{The Categorical Approach versus the Symptom-Based Approach}

Clearly, the most obvious benefit of accurate categorization is in identifying those individuals who are a danger to themselves and others and those who are not; those who warrant confinement and those who can exist with support in the wider community. There may also be considerable relief for the sufferer and their family to have a diagnosis and therefore a potential pathway for treatment. This will most likely be the case for many disorders, but will be more complicated for those with significant associated social stigma such as schizophrenia. Categories also facilitate easier communication between mental health professionals, provide justification for research funding, and serve as an efficient means of ascertaining eligibility for pharmaceutical interventions, health and welfare services, insurance, and also culpability with regard to the law.

Despite the above-mentioned benefits, there is the very real and persisting concern of accuracy in categorization-based diagnosis, arising from demarcation problems when there are comorbidities, which is most often the case, ${ }^{4}$ along with the well-documented problem of symptom amplification [36, 37]. Stigmatization and looping effects ${ }^{5}$ will also complicate any diagnostic process $[38,39]$. There is also the issue of conflict of interest when there is adaptation of diagnostic assessments to match the criteria needed for access to services, for pharmacological interventions, for insurance and for research funding. And this last issue puts immense pressure on the interviewing psychiatrist not only because of the inadequacies of fixed diagnostic classifications themselves but also because the psychiatrists may be forced into morally invidious situations. And we can add to these

\footnotetext{
${ }^{4}$ This may be less of a problem for ICD-10, which is a hierarchical system, than for DSM classification. There are few psychiatric assessments which could claim a definitive diagnosis; for the most part they include comorbidities and "not otherwise specified" diagnoses. For the DSM, while exclusion criteria serve to an extent to reduce multiple diagnoses, all diagnoses are listed if the criteria are met. In contrast, for the ICD-10 a diagnosis with a code higher in the hierarchy will generally override any diagnosis with a code lower in the hierarchy, effectively avoiding multiple diagnoses for the one patient, but at the same time possibly ignoring symptoms that may be an important aspect of the presentation of the patient.

5 "Looping effects" is the term coined by Ian Hacking to refer to the impact that psychiatric classification has on the person classified; generally exacerbating and entrenching the symptomatology of the person as classified. $\mathrm{He}$ writes: "People of these kinds can become aware that they are classified as such. They can make tacit or even explicit choices, adapt or adopt ways of living so as to fit or get away from the classification applied to them ..... I have called this phenomenon the looping effects of human kinds" [38].
}

concerns the fact that categorization-based diagnostic approaches have been and may continue to be susceptible to social and political agendas. As long as the categories continue to be reified and regarded as a definitive assessment of the mental state of the patient, these issues will persist.

The proponents of a phenomenological or descriptive approach argue that focusing on symptoms keeps the information relevant to the individual and is less susceptible to arbitrary decisions and socio-political interference [40-43]. ${ }^{6}$ This approach is also better equipped to identify mental health issues in the prodromal stage and to take account of contexts and changes in patients over time. Those opposed to this approach, however, argue that it is too superficial and cannot address the causes of the mental disorder. Thus, treatments will be "band-aid" only, not getting to the basis of the disorder. And furthermore, the advantages of the categorical approach, it is argued, are reversed or become impossible to clinically implement in this pure symptomatological approach.

In their essay "The Secret History of the ICD and the hidden future of the DSM," psychiatrists Fulford and Sartorius [44] expose some of the key philosophical and political tensions surrounding the historical debates with regard to the often opposing priorities of the categorization-based theoretical (etiological) approach and the phenomenological-descriptive (symptom-based) approach to psychiatric classification. They offer a careful historical corrective of the various contributions to the classificatory systems for the ICD and identify Audrey Lewis, the later Head of The Maudsley School, as the originator of the suggestion to "eshew categories based on theoretical concepts" and focus instead on descriptive classification. Lewis also made the distinction between "public classification" and "private classification,"7 allowing thus for a flexible approach for private classifica-

\footnotetext{
${ }^{6}$ Specifically, phenomenological approaches help to undermine reification which is sometimes the result of stringent (and often ideologically motivated) practices of classification, and which lends itself to arbitrary decisions and sociopolitical interference. The stand-out example is the category of "homosexuality" pre-1973. Phenomenological approaches, together with PTS, stay close to the description of signs and symptoms and avoid any overlay with fixed or ideological categorical definitions.

7 "'Public classifications [as Lewis explains] are the kind that are most valuable for epidemiological work, since we need to make comparisons of findings in different countries, and unless there is uniformity of usage, that is impractical'. [Whereas private classifications], by contrast, may be used by particular groups (including particular research groups, presumably) who have, '... a uniform background $\ldots$ and have agreed among themselves as to the usage of the [relevant classificatory] terms'." [44]. This analysis coheres well with the "field guide" approach mentioned earlier.
} 
tions pragmatically tailored to specific domains, such as research or the clinical setting [44]. The big problem, according to Fulford and Sartorius, is not so much in the efficacy of descriptive symptom-based classification but that it has been used in domains where it is not suited. As they note, Lewis had already insisted that for the purposes of public classification, descriptive symptom-based classifications worked well. However, the problem has arisen in the use of descriptive symptom-based classifications for administrative purposes such as determining access to clinical care, for legal proceedings and also for research. They make the comparison with current physics where relativity maps the macro-physical world and quantum mechanics maps the micro-physical world; neither theoretical framework can account for both levels of reality [44].

Aside from the issue of addressing the intrinsic complexities of mental illness, the DSM is an instrument that is also being made to serve different masters with very different priorities, furnishing researchers with verifiable categories and causes for investigation; clinicians with understanding and treatment strategies; insurance companies with assessment criteria of eligibility for claims; service providers with clear eligibility criteria for pharmacological treatments and welfare support; the legal system in determining responsibility and in protecting the individual and wider society from potential harms; and ultimately the person suffering anomalous experiences whose basic right to self-determination may be called into question [23, 45-47]. The key question is whether we need an entirely different assessment system which can answer the needs of all these different players or whether we accept that this is an impossible task and aim for variations in assessment methodologies that are workable in different contexts, but perhaps not theoretically and pragmatically consistent? Or, is there another way of re-conceptualizing the issue of psychiatric assessment? Our suggestion is that while the categorical frameworks are useful as a tentative guide which will necessarily be revised as more information comes to light and as the experiences of the patient under consideration evolve or devolve, a more comprehensive and accurate understanding of anomalous experience is achievable through a "rich diagnosis" as we detail below.

In psychology and psychiatry, invoking reductionist theories of causation, natural kinds and classificatory frameworks have proven to be at best of limited value in understanding and treating mental disorders. Parnas and Gallagher [48] set out the problem of the categorial- classificatory checklist approach thus: "The psychiatric object is typically portrayed as an objective, thinglike entity, unproblematically graspable as it exists in itself through a behaviorist third-person perspective and as being indicative of a specific and modular physiological dysfunction." This oversimplification of the "psychiatric object" and the epistemological reductionism involved in the Structured Diagnostic Interview as initially established through the DSM III's project to operationalize diagnosis [49], they propose, are key to the crisis of legitimacy in psychiatry. As they explain, this crisis in confidence is evident in the redirection of research funding away from the traditional narrow diagnostic categories towards broader domains of psychopathology and neuroscientifically verifiable behavioral constructs, such as the NIMH Research Domain Criteria [RDoC] [50]. And while it is widely acknowledged that the RDoC is effective for research, it is not helpful for clinicians. The upshot is that clinicians remain stuck with the evaluative deficiencies of the DSM checklists $[17,18,26,51-53]$.

We acknowledge that the DSM has undergone various evolutions. Notably DSM III (1980), which abandoned the purely typological approach of DSM II based on causal-etiological investigations, for one that emphasized precise description of criteria in terms of clusters of symptoms, organized under 5 Axes [49]. It is interesting to note that despite the fact that with Axis IV, social and environmental factors are given recognition as integral to this supposed biopsychosocial model, the emphasis remained on the biological; as Scharfstein coined it this model was in effect the biobiobio model [54]. The change from prototypes to criteria-based diagnoses was later adopted by ICD-10. Both systems are now focused on phenomenological-descriptive assessments and protocols oriented towards categories without fixing these solely in terms of etiology. Such a positive change, notwithstanding, we suggest that a further evolution is needed, as we outline in the following sections.

\section{Karl Jaspers' Phenomenological Approach}

Karl Jaspers' text General Psychopathology [32, 33] remains an important reference in psychiatry [55]. Jaspers offers a balanced and optimistic approach to addressing the imperfections of psychiatric theory and methodology. The reason why classifications must only be granted provisional status is that, as Jaspers writes: "It is difficult to bring diagnostic order ... into shifting phenomena which
Daly/Gallagher 
continually keep merging into one another...." $[32,33]$. Typologies, thus, can enhance "our understanding at any time of the essential connectedness of many phenomena but [they deal] with ideal forms to which reality only more or less approximates" $[32,33]$. Distinctions between types, or diagnostic categories, are not definitive, nor is the distinction between what would be considered "normal" or "abnormal." Indeed, it is clear that Jaspers' aim was antithetical to the whole idea of the DSM, i.e. to establish a definitive system of classification and a neurobiologically justifiable explanation of psychopathology. Jaspers was aiming for neither theoretical nor methodological closure $[32,33]$, but rather, his priority was to establish an open attitude of compassionate, empathic attention to and curiosity about the experience of the person appearing before him while at the same time recognizing the impossibility of fully grasping the other person's experience and world. The person who ultimately knows her own experience, is the patient herself; the interviewing psychiatrist's role is to facilitate disclosure, to clarify where possible on the basis of their training and experience, and to negotiate a means of allaying suffering.

Jaspers' methodology was informed by three principles. First, he employed some of the strategies of phenomenology so as to focus on the lived, first-person experience of the patient. Phenomenology ${ }^{8}$ brackets out causal explanatory frameworks whether from biology, neurology or theories of unconscious forces such as psychoanalysis. Second, he promoted the distinction, originally advanced by Dilthey, between causal explanation which draws on the strategies and technologies of medical science, and psychological understanding, the establishment of a meaningful rapport between psychiatrist and patient for interpreting the patient's behavior and experience. For Jaspers explanation and understanding were complementary but distinct. Furthermore, Jaspers was interested in understanding the whole person, not just in establishing a precise symptomatology. Importantly, all the classifications he described included the social dimension

\footnotetext{
${ }^{8}$ The term phenomenology has various usages. Above it is used to refer to the tradition originating with Edmund Husserl which places "lived experience" at the core of its modus operandi, eschewing "the natural attitude" of common-sense assumptions and theoretical commitments overlaying experience. Phenomenology as a philosophical/psychological practice goes beyond the way the term is commonly understood within analytic philosophy and classical cognitive science which equate it with "the what-it-is-like to have an experience." What is often overlooked in the latter focus are the further implications of this "lived experience," such as the importance of firstperson perspective, situatedness, and the enactivist intervolvements across different dimensions.
}

Towards a Phenomenology of Self-Patterns and remained tentative and always open to revision. The third principle focused on the relationality of psychopathological phenomena. According to Jaspers, and contrary to the then current view, method and fact are interdependent. He writes: "We obtain our facts only by using a particular method. Between fact and method no sharp line can be drawn. The one exists through the other. Therefore, a classification according to the method used is also a factual classification" $[32,33]$. And later he writes: ".... classification of method introduces an order into observed facts which is in accordance with the order of those facts... [and moreover] classification is a task which never finishes" [32, 33].

We argue, in the following sections, that the PTS combined with the methodology of a phenomenological inter$v i e w^{9}$ offers a viable means to implement Jaspers' phenomenological approach. This approach is also in line with Merleau-Ponty's observation that illness involves an altered way of being in the world, and is, accordingly, a "complete form of existence" $[63,64] .{ }^{10}$ Specifically, we propose to extend and expand the interpretative framework developed in contemporary phenomenological psychiatry which understands schizophrenia as a self-disorder, understood specifically as a disorder of ipseity or the minimal self [58, 34]. Employing PTS, we argue that all psychiatric disorders are self-disorders, understood in a wider sense to mean varied disorders in self-patterns. ${ }^{11}$ As Parnas and Gallagher put it:

Psychiatry needs a framework that will help characterize the more complete picture (the positives as well as the negatives) of how illness has made the patient's life different. This would provide what we might call a rich diagnosis. The kind of practice needed to get this diagnosis, the attempt to gain a deeper understanding of the complete form of existence, is one that looks at the human as an extended system - an embodied and embedded living system dynamically and enactively related to its surroundings - and that takes this system as the unit of analysis [48].

Such an approach represents a significant reconfiguration of the manner in which the "psychiatric object" is

\footnotetext{
${ }^{9}$ There are a number of interviewing methodologies inspired by phenomenology: the EASE by Parnas et al. [58]; and some that originate in the work of Francisco Varela [56], the elicitation interview by Pierre Vermersch [57] and the micro-phenomenology interview by Petitmengin [59], Petitmengin \& Bitbol [60]. For reviews of such methodologies see Olivares et al. [61], Høffding and Martiny [62].

${ }^{10}$ For insightful analyses of illness which draw on Merleau-Ponty's works, see Carel [65].

${ }^{11}$ See Parnas and Handest [66]; This approach is compatible with that of Stanghellini and Broome [26] who defend the claim that there is a need to refocus on psychopathology as the discipline investigating abnormal subjectivity rather than diagnostic categories.
} 
perceived and treated; $\mathrm{s} / \mathrm{he}$ is no longer conceived in caus$\mathrm{al}$, mechanistic and reductive physicalist terms, but in the full dynamical multidimensionality of the person immersed in a meaningful world. ${ }^{12}$ This approach coheres well with Jaspers' view, respecting the first-person reports of the patient suffering anomalous experiences, and enabling a precisely targeted assessment of the individual which not only tracks changes but also, through compassionate attention, simultaneously serves as an aspect of treatment [30]. This approach also goes some distance in resolving a number of issues for psychiatric assessment such as vagueness and the demarcation problem with regard to comorbidities [68], stigmatization [69, 70], and symptom amplification [36, 37]. Appeal to PTS circumvents these issues because it is not making any interpretive judgment based on diagnostic categorical classifications, such as "these symptoms indicate schizophrenia and not depression." In this way, the challenge of demarcation when there are comorbidities, one of the most difficult aspects of diagnosis, is no longer an issue. This alternative method is only noting aspects of the self-pattern that are challenged or interrupted in the 1st person experience or in 3rd person observation (including neurological observations), and these may be present as much in the experience of the "normal" as in the "abnormal." Stigmatization is thus also less likely.

\section{The Pattern Theory of Self}

What constitutes "self" remains a notoriously contentious issue within philosophy, psychology, and psychiatry. In the history of philosophy and psychology, there has been the assumption that "self" is a persisting, unified, and transparent locus of experience and that factors external to the embodied self are contingent and adventitious, whereas factors internal to the embodied self are more essential and definitive. Traditionally "self-disorders" have been more narrowly confined to the sense of loss of unity, transparency and agency. Interestingly, beyond the classical Humean and Buddhist views, the question as to whether there is even such a thing as a "self" has been motivated by recent neuroscience. Metzinger [71], for example, claims that there is no real self, but only a model generated by the brain's neuronal processes. ${ }^{13}$

\footnotetext{
${ }^{12}$ See Gallagher and Varga [67] for an investigation into social cognition and psychopathology.

${ }^{13}$ See Kelly [30] for a more accurate and comprehensive account of this Buddhist-inspired notion.
}

The relation between self and brain continues to be an open question. Northoff and Bermpohl [72], Northoff et al., [73], and Northoff and Panksepp [74], for example, have identified the cortical midline structures (CMS) as being the location correlated to self-referential processes in the brain. However, alternative interpretations propose that not only is the CMS not exclusively correlated with self-specific processes [75] but that "the self is both everywhere and nowhere in the brain" [76, see also 7779], which suggests that the self is neither reducible to particular brain processes nor neuroscientifically unimportant. And so, just as locationist theories in the history of psychiatry seeking the correlative lesions in the brain for specific types of mental disorder have remained impossible to sustain, so too the efforts to find the precise neural correlates of selfhood and self-disorders remain elusive.

A more dynamical perspective has recently been taken up by Fingelkurts and Fingelkurts [80]. They found significant correlations between severity of symptoms in major depressive disorder (MDD) and increased connectivity within each module of the self-referential brain network "contributing to excessive self-focus, rumination and body-tension" [80]. Rather than neural correlates, however, they stress that "it is important to keep in mind that the three aspects of selfhood, indexed by the three operational modules [self-focus, self-reflection and selfrelated emotions], are not entities that simply modify something that has its own independent existence, but rather together form a dynamic pattern, that as a whole constitutes a complex selfhood...." [80]. Just here they reference PTS [81]; see also [30, 82].

In many theories of the self, just one thing is identified as self; for example, the self just is the minimal experiential self, or the ecological self, or the self as an object of reflective self-consciousness, or the social self, or the narrative self (see Strawson [83] for an extended list of different conceptions of self). This clearly indicates that the concept of self can include many different things. PTS is a pluralist approach that includes a variety of self-aspects and encompasses the concerns of both internal and external approaches. It eradicates the need to locate a self-disorder as either internal to the subject or external, out there in the social world. According to PTS, self is not limited to internal or external elements; it is not any one of these elements, nor is it a simple list or collection of elements. The self is a pattern, a dynamical gestalt, and what is important is the connectivity and the dynamical relations of the self-aspects [84]. PTS not only clarifies and demonstrates the compatibility of the various inter-
Daly/Gallagher 
pretations of self, but also has the potential to afford a versatile and adaptable instrument for applied domains such as psychiatry.

PTS proposes that what we call self consists of a complex pattern of factors or contributories, none of which on its own is sufficient to any particular self. Accordingly, what we call "self" is a cluster concept which includes a sufficient number of characteristic features to constitute a pattern. According to PTS, selves operate as complex systems that emerge from dynamical interactions of constituent elements. The dynamical relations or interactions among the various factors are important for defining the pattern as a dynamical gestalt that can change over time. The list of elements or aspects, which may take on different weights and values at different times, should not be read as a list simpliciter, but as a set of relata which help to define a dynamical pattern $[80,83]$. The relata include the following elements.

1 Embodied aspects - general physical health, and core biological aspects that have a direct effect on one's life, e.g. CNS, autonomic and hormonal functioning, sleep patterns, diurnal rhythms, as well as sensory-motor (ecological) processes which allow the system to distinguish between itself and what is not itself, including the egocentric (body-centered) spatial frame of reference, which grounds a first-person perspective, and contributes to specifications of possible actions in peripersonal space.

2 Experiential aspects - to the extent that such embodied factors are conscious, one's experiential life includes a pre-reflective, embodied consciousness characterized by the first-person perspective, and the senses of ownership (mineness) and agency which incorporate various sensory-motor modalities, such as proprioception. These aspects, tied to a first-person perspective, form the experiential core of what is usually called the minimal self (or minimal self-awareness) [85].

3 Affective aspects - temperament and emotional dispositions reflecting a particular mix of affective factors that range from very basic and mostly covert or tacit bodily affects to typical emotional expressions [86].

4 Behavioral aspects - behaviors and actions make us who we are - behavioral habits reflect, and perhaps actually constitute, our character. This is a classic view that goes back at least to Aristotle.

5 Intersubjective aspects - including the very basic capacity for attuning to others found in infancy [87], and more developed forms of self-consciousness, e.g. a sense of self-for-others [88]; a self-conscious recognition of oneself as being oneself as distinct from others, as well as the sense of being part of a group or community. This also includes non-conscious aspects of the social self originating in intersubjective/social interactions [89].

6 Psychological/cognitive aspects - including reflective self-consciousness, self-evaluation, one's conceptual understanding of oneself, personality traits. These aspects get interpreted within the dominant theories of personal identity that point to psychological continuity, memory, and representational accounts of identity [90].

7 Narrative aspects - on some theories, selves are inherently narrative entities and for some theorists, narratives are constitutive of selves [91]. Self-interpretation has a narrative structure and recursively reflects (and often reinforces) the self-pattern.

8 Extended/situated/normative aspects - we identify ourselves with stuff we own [92], and with the technologies we use, the institutions we work in, etc. This includes structures and environments that shape who we are such as family, culture, and normative practices. Such things may become incorporated into the sense of self and can become key to self-identification.

The key point is that the self cannot be reduced to any one of these aspects. Indeed, one or more of these elements can be disrupted, as we might find in various psychiatric disorders. But a pattern, that is, a self, remains as long as there are a sufficient number of elements remaining in dynamical relations. ${ }^{14}$ Although it is philosophically interesting to ask whether any one of these elements is necessary or essential, ${ }^{15}$ for psychiatric purposes it is more relevant to ask under what circumstances any particular aspect gets disrupted, and how that disruption changes the dynamical pattern itself. That is, if memory and narrative are challenged in Alzheimer's disease, or if the sense of agency is disrupted in some forms of schizophrenia, or bodily control in Parkinson's disease or catatonia, nonetheless, a self-pattern or self-identity, in some form, persists and can be supported by the remaining aspects more or less effectively. At the same time, with a change in any one element, above a specific threshold, the self-pattern as a whole (as a complete form of existence) can change, in the same way that a dynamical gestalt changes when any part of it changes. For ex-

\footnotetext{
${ }^{14}$ In some extreme cases, a self-pattern may be entirely disrupted - for example, in some cases of torture, or as a result of prolonged solitary confinement $[43,93]$.

${ }^{15}$ The most obvious candidates for being essential to the self are the embodied and experiential aspects of the self-pattern, and these are interdependent. Following Merleau-Ponty, we can say that any account of perception is also an account of embodiment, not only in the specificities of that body, but also in that we are always "this side of our body," i.e. there is the sense of ownership or mineness in non-pathological experience. Nonetheless, for a full account of "self" more is needed.
} 
ample, with Alzheimer's syndrome, as a direct result of the disruption to memory the affective dimension and intersubjective relations will be altered because the patient may not recall the significance of an individual in their earlier relations - that the individual is in fact his daughter or had been a person who had exploited or betrayed them. So too cultural and normative practices that were held dear or were a habitual aspect of the person's engagement in the world may drop away entirely or may only be episodically in evidence. Nonetheless, as indicated above, if there are enough of the aspects of the selfpattern functioning in a sufficiently coherent manner, the person is still recognizable as being the person he was. PTS thus ensures a non-reductive and non-deflationary account of self that takes the pattern to be pragmatically, scientifically real ${ }^{16}$ while eschewing both the traditional notion of the atomistic, Cartesian soul-self and the reductive physicalist self found in much current science.

Why might PTS present anything new and advantageous in regard to psychiatry compared to what is already on offer? Increasingly, many mental health disorders are recognized as being disorders of the self, which can be interrogated across multiple dimensions. For example, there have been insightful investigations of disrupted selfexperience, self-identity or self-agency in schizophrenia $[26,34,58,96,97]$, disturbed bodily experience in schizophrenia and other disorders [96, 98-101], as well as in analyses of depression and anxiety $[102,103]$ which draw on phenomenological and enactive concepts of self entirely compatible with PTS. The PTS thus offers a unified theoretical framework for analyzing and tracking the evolution of these self-disorders [104].

We can learn about such changes or transformations of a self-pattern from what the patient reports, e.g. she may report (or her reports may reflect) the loss of a sense of agency, as in some schizophrenic symptoms, or in addiction, without losing other basic experiential elements that are part of a self-pattern. The patient may report or exhibit loss of certain psychological and cognitive abilities, such as the ability to recall their earlier life (amnesia; Alzheimer's disease), and they may have undergone character or personality changes that may be reflected in their narratives. In such cases, some degree of self-identity and autonomy may continue to be supported by the minimal bodily and experiential aspects, by intersubjective relations and/or extended aspects in their surroundings. In the case of depression, the patient may reveal thinking

\footnotetext{
${ }^{16}$ See the discussion of real patterns in Dennett [94] and Haugeland [95].
}

that reflects disorders in mood and affective processing as well as disrupted processes connected to the sense of agency and identity. Depressed patients can experience self-alterations, identity changes, and they will attempt to integrate these changes into their life by trying to understand the reasons they are feeling this way. They will typically report feelings of inevitability, inability, helplessness, desperation, self-loathing, and the incapacity to work, to act, to think clearly [105-109]. In various depressive narratives, alterations in what Matthew Ratcliffe [102] calls existential feelings can be mapped out across different components of the self-pattern [98, 99, 107, 110]. In a variety of ways, these problems or symptoms may be reflected in a patient's narratives. It is also possible, however, that narrative structures, including temporal and syntactical structures, may be disrupted, for example, in schizophrenia [111-114] or depression [103, 114-117] or dysnarrativa [118]. ${ }^{17}$ This is a complication discussed in the next section where we suggest that selfnarratives may reflect all of the other elements of the selfpattern.

In taking the notion of a self-pattern to be the basis of a non-reductive approach to understanding psychiatric disorders, we do not intend to exclude objective thirdperson measures such as genetics and neuroscience, or to downplay the importance of brain function, which at a certain level of analysis underpins many of the aspects of a self-pattern. ${ }^{18}$ Indeed, on a complementary third-person approach one can say, as Fingelkurts and Fingelkurts [80] suggest, that changes in neurophysiology can "index" changes in the self-pattern, complementary to the way that narrative reflects such changes [84].

The list of elements or contributories to, and the dynamical relations within the self-pattern can be used to specify most if not all aspects relevant to symptomology in psychiatric cases, as well as the general sense of self of those not requiring psychiatric interventions. In this way, it is possible to situate individuals on a multi-dimensional continuum, so that there are no longer sharp distinctions between the supposedly "normal" and the "abnormal"; anyone may be challenged with regard to any aspects of their self-pattern, to greater or lesser extents. The key question becomes: Are any of the chal-

\footnotetext{
${ }^{17}$ The inability to tell and understand stories often found in cases of Korsakov's Syndrome and Alzheimer's Disease.

${ }^{18}$ For example, with regard to something like MDD, there may be genetic predisposition [119]; likewise, there may be objectively measurable hippocampal shrinkage [120]. In addition, there may be high uptake or turnover in serotonin [121]. Any such biological changes, i.e. changes in the embodied aspect, will have an effect on other aspects of the self-pattern.
}

Daly/Gallagher 
lenged aspects, individually or collectively, interfering with the autonomy and positive social engagement of the individual?

\section{Narrative as Reflecting the Self-Pattern and as a Second-Person Practice}

Although in various therapeutic contexts it may be obvious or more fruitful to focus on one or other of these elements/factors, and indeed, there may be more than one therapeutic practice that can address different factors and different pathologies, we will focus here on a narrative route into the pattern as a way to map the disorders of the self. Self-narratives in some sense reflect, explicitly in content, or implicitly in form, all of the other aspects of the self-pattern [122]. Narrative is thus a means of retrieving, disclosing, temporally mapping, and connecting all the other aspects. In psychiatric contexts, it is one key to tracking both the evolution of the disorder and the therapeutic process. Furthermore, we propose that narrative can be put to use in therapeutic contexts in the form of a second-person phenomenological interview.

Narratives that focus on the first-person experiences of the narrator, generated in interactive contexts of conversation or in semistructured interviews have immense value across all medical contexts [123]. Indeed, we may learn about other aspects of the self-pattern precisely through a patient's narrative, not only in terms of narrative content (what the patient tells us about herself), but also in terms of narrative form (how the patient does the telling $[124,125]$. Importantly, outside of any psychiatric context, some subjects may experience their lives in a less coherent and more episodic manner than most other people [126]. In such cases, the narrative aspect may be diminished as part of the self-pattern; nonetheless, we can still say that self and self-identity persist, supported by and tracked according to the other aspects of self.

More positively, in therapeutic contexts, a patient/interviewee may incorporate any new awareness, such as becoming more aware of her body, or any new adjustments in her life, into her continuing narrative. We can formalize the use of narrative in therapeutic contexts not just in the sense of using a narrative therapy [113, 127-130], but also in conjunction with other therapies $[122,130]$. In this regard, formalizing the use of narrative involves accessing the patient's first-person experience by using a second-person method, namely, the phenomenological or microphenomenological interview (see the next section). Phenomenological interviews are second-per-

Towards a Phenomenology of Self-Patterns son or intersubjective, not only in the obvious sense that they involve a dyadic interaction between interviewerphysician and interviewee-patient, but also in the sense that much of what the patient discovers and expresses in her narrative emerges only in the expression of it to the other person, the interviewer-physician, who is attempting to understand. In such cases, we can say that the processes that lead to these detailed descriptions or narratives are not private mental procedures, but intersubjective, interactive accomplishments. This kind of intersubjective narrative dynamic has direct application to clinical reasoning in various medical and therapeutic practices - physical medicine, psychiatry, physical therapy, psychotherapy $[131,132]$.

Narrative is playing a double role in the therapeutic context. First, as the part of the self-pattern that is reflective of other parts, it is a window or mode of access (for both patient and therapist) into the pattern, and a way to explore the precise details of the self-pattern. This is the role of narrative that allows for its formalization in the second-person phenomenological interview. Second, as part of the pattern itself, and because of the dynamical nature of the pattern, a change in self-narrative can recursively effect a change in the pattern as a whole. ${ }^{19}$ In this respect, narrative is like other elements in the self-pattern that may be useful in therapy, since any change in any of the elements of the self-pattern may have an effect on the pattern as a whole. For example, bodily practices (in movement or dance therapy, or body psychotherapy) may also facilitate a change to the pattern as a whole. Behavioral changes, cognitive changes, or changes made to the patient's environment may also serve this purpose.

It is important to note two complications that may arise with respect to a patient's self-narrative, even as it may get developed in phenomenological interviews. First, as mentioned above, the structure (and not just the content) of a patient's self-narrative itself may be affected by a particular disorder. This can both provide clues to the therapist, and make the patient-therapist relation more challenging. In more severe cases, this may be the most challenging aspect of psychopathology for the psychiatrist, as Jaspers himself realized [32, 33]. Second, in some cases, changes to a patient's self-pattern (e.g., some personality changes) may not be apparent to the patient and may not show up in the patient's narrative. The therapist, using methods of phenomenological interview, can explore other aspects of the self-pattern (espe-

\footnotetext{
${ }^{19}$ Jaspers has written: "Man is not merely pattern, he patterns himself" [32, 33].
} 
Table 1. Map of the symptomatology of depression in terms of the PTS framework

\begin{tabular}{|c|c|c|}
\hline $\begin{array}{l}\text { PTS - elements } \\
\text { of self-pattern }\end{array}$ & DSM-5: symptomatology for depression & Case reports/first-person interviews ${ }^{\mathrm{a}}$ \\
\hline Embodied aspects & $\begin{array}{l}\text { Significant weight loss when not dieting or } \\
\text { weight gain (e.g., a change of more than } 5 \% \text { of } \\
\text { body weight in a month), or decrease or increase } \\
\text { in appetite nearly every day } \\
\text { Insomnia or hypersomnia nearly every day }\end{array}$ & $\begin{array}{l}\text { Lack of appetite } \\
\text { Sleep disturbances } \\
\text { Sleepiness, but sleep is not refreshing }\end{array}$ \\
\hline Affective aspects & $\begin{array}{l}\text { Depressed mood most of the day, nearly every } \\
\text { day, as indicated by either subjective report } \\
\text { (e.g., feels sad, empty, hopeless) or observation } \\
\text { made by others (e.g., appears tearful) } \\
\text { Markedly diminished interest or pleasure in all, } \\
\text { or almost all, activities most of the day, nearly every } \\
\text { day (as indicated by either subjective account or } \\
\text { observation) } \\
\text { Feelings of worthlessness or excessive or inappropriate } \\
\text { guilt (which may be delusional) nearly every day (not } \\
\text { merely self-reproach or guilt about being sick) }\end{array}$ & $\begin{array}{l}\text { Loss of empathic resonance with others } \\
\text { Loneliness } \\
\text { Self-loathing or low self-esteem } \\
\text { Pervasive sense of dread } \\
\text { Unaccountable fears } \\
\text { Feeling that their experience is absolutely private } \\
\text { and absolutely isolating } \\
\text { Despair } \\
\text { Sense of worthlessness or purposelessness } \\
\text { Feeling of being excluded, not understood, underappreciated } \\
\text { Self-alienation ("I would never belong to a club that would have } \\
\text { someone like me as a member") }\end{array}$ \\
\hline Behavioral aspects & $\begin{array}{l}\text { Psychomotor agitation or retardation nearly every } \\
\text { day (observable by others, not merely subjective } \\
\text { feelings of restlessness or being slowed down) }\end{array}$ & $\begin{array}{l}\text { Inability to stop crying } \\
\text { Diminished physical self-care } \\
\text { Self-harm which reduces anxiety }\end{array}$ \\
\hline Intersubjective aspects & & $\begin{array}{l}\text { Feeling like a burden for others, like a loser } \\
\text { Feeling excluded - feeling of not belonging, profound } \\
\text { intersubjective alienation } \\
\text { Concern that others think they are malingerers } \\
\text { Mirror self - negative assessment } \\
\text { Feeling invisible } \\
\text { May have experienced childhood maltreatment }\end{array}$ \\
\hline Narrative aspects & & $\begin{array}{l}\text { Repeatedly re-scripting conversations that were deemed } \\
\text { unsatisfactory } \\
\text { Predominance of use of first person pronouns } \\
\text { Past narratives are couched in terms of loss, failure and damage } \\
\text { Present narratives hold little or no interest } \\
\text { Future narratives have dried up }\end{array}$ \\
\hline $\begin{array}{l}\text { Extended/situated/ } \\
\text { normative aspects }\end{array}$ & & $\begin{array}{l}\text { Loss of the sense of personal salience of these things and } \\
\text { entities (lack of care for loss or damage) } \\
\text { Loss of sense of belonging } \\
\text { Diminished engagement, joy and pride in the above }\end{array}$ \\
\hline
\end{tabular}

${ }^{a}$ The descriptors in the above table have been collated from various sources, notably [98, 102-108, 115, 119, 120, 121, 136-146]. 
cially intersubjective and extended/situated aspects) to bring the patient to an awareness of these changes in a way that will allow for them to be incorporated into the self-narrative.

It is revealing to compare and contrast DSM-5 categories with data from case studies and patient interviews and narratives to see how they line up with the various elements of PTS. This strategy was proposed by Dings and de Bruin [133] in relation to their work on the therapeutic use of deep brain stimulation ${ }^{20}$ in cases of obsessive-compulsive disorder (OCD). They mapped the DSM-5 definition of OCD onto PTS and found that all aspects of the symptomatology were mapped perfectly in PTS. Following that strategy, and drawing on case studies, vignettes, and phenomenological reports, we have devised an integrated mapping of the symptoms of MDD according to the descriptors of DSM-5 onto the PTS (Table 1). Not only did all the DSM symptomatology for MDD map onto PTS, but, in addition, case studies and first-person reports of depressed persons reveal significant gaps in the DSM-5 descriptors.

\section{Phenomenological Interviews}

The phenomenological interview methods (examples of which include the Examination of Anomalous Self-Experience - EASE [58], the elicitation Interview [57, 147], and the micro-phenomenological interview $[59,148]$ ) aim to facilitate enhanced awareness of subjective experience for the purposes of precise description. Both the enhanced awareness and the precise description rely on skills requiring training or guidance because of the inherent difficulties of accurately communicating first-person experience. Such an approach is not new; it is prefigured in the Buddhist traditions of shamatha-vipassana meditation and also in neurobiologist Francisco Varela's initial elaboration of the need for such a method [56]. ${ }^{21}$ Unlike the meditative situation, which does not require communication and concerns only the experience of the meditator, the interview involves two individuals each bringing their own expectations and understandings to the process. And this is why for the interview to achieve its aims of accessing and understanding the experience of the interviewee, the interviewer must minimally have an atti-

\footnotetext{
${ }^{20}$ For another phenomenologically inspired investigation into DBS see de Haan et al. [134]; and its ethical implicatons, see Lipsman and Glannon [135]. ${ }^{21}$ See Lutz, et al. [149] for an early implementation of these ideas and methodologies in scientific experiments; also Olivares et al. [61].
}

tude of good will and furthermore establish an adequate level of empathic availability towards the interviewee $[25$, 32, 150-152].

Even if empathy is established, this does not make the process "foolproof." There will still be challenges since ambiguities, change, and interpretation are in the very nature of first-person experience. For these reasons, the investigation of subjective experience has been historically regarded with much suspicion on the part of those seeking the supposedly objective standards of science. As Varela and Shear rightly point out, however, this first challenge of fallibility applies to all methods, including scientific methods. ${ }^{22}$ They write:

Indeed, no methodological approach to experience is neutral, it inevitably introduces an interpretative framework into its gathering of phenomenal data. To the extent that this is so, the hermeneutical dimension of the process is inescapable; every examination is an interpretation, and all interpretation reveals and hides away at the same time. But it does not follow from this that a disciplined approach to the experience creates nothing but artifacts, or a "deformed" version of the way experience "really" is [150].

In order to render first-person experience scientifically useful, it must be first accessed and then communicated; and so precise description becomes paramount and such precision in the psychiatric interview is not easily achieved for a number of reasons, and this represents the second significant challenge. In general, even with subjects who are not suffering anomalous experiences, becoming aware of our subjective experience is difficult for a number of reasons: firstly, our attention is usually dispersed rather than focused; secondly, our attention is absorbed in the external world and events, and so selfawareness remains tacit; and finally, there is the fact that our engagement with the world is primarily pre-reflective and pragmatic (involving knowing-how rather than knowing-that) and not easily put into words $[63,64,59$, $100,153]$.

The third challenge in becoming aware of our subjective experience is that there is often a confusion between experience and representation of the experience; "not only do we not know that we do not know (how our

\footnotetext{
${ }^{22}$ As noted above, phenomenological methodology and various forms of phenomenological interview have been used in experimental designs. Although Husserl conceived of phenomenology as a transcendental project (which he called a rigorous science), he also recognized its relevance to empirical science, as a form of phenomenological psychology, for example. Our claim is consistent with this: phenomenology is both extremely pertinent to and vindicated in the scientific investigations of the mind and psychopathology.
} 
cognitive processes take place), but we believe that we know - we have a mistaken representation of our cognitive activity" [57]. Drawing on Vermersch and Piaget, Petitmengin describes two effects of these misapprehensions; firstly, a deforming effect in that we tend to replace the description of the experience with a description of a representation of the experience; secondly, a concealing effect so that when aspects of the experience do not conform to our expectations as represented to ourselves, we discard or repress them. In order to access the experience itself it is thus necessary to let go of or bracket the representations, beliefs, judgments and internal commentaries. ${ }^{23}$ As the various versions of the phenomenological interview recommend, a trained guide/interviewer is of benefit to overcome these tendencies and to constantly redirect the attention of the interviewee back to the experience itself; not to become caught up in abstractions, justifications, or explanations of the experience but just to disclose the experience as lived in a particular time and place. Various versions of the phenomenological interview have detailed a number of strategies ${ }^{24}$ for achieving this presence with the lived experience drawing on Buddhist psychology, Eriksonian language, ${ }^{25}$ mainstream psychological practice and neurolinguistic programming. As Høffding and Martiny [62] in their review of the various phenomenological interview approaches assert, it may not be necessary to establish an authentic re-living or re-enactment of the original experience, which is the aim of the micro-phenomenological interview, but rather to attain sufficient understanding of the experience of the interviewee so as to discover the invariant phenomenological structures of the experience [62].

Converting the subjective experience into language is yet another challenge. Because the interviewee is asked to

\footnotetext{
${ }^{23}$ Anyone familiar with Buddhist meditational techniques will recognize these difficulties and the respective "antidotes."

${ }^{24}$ Staying focused on the particular and avoiding slipping into generalizations, justifications and explanations; regular reformulation of the experience as described, thereby bringing the interviewee back to the task of describing the lived experience; being attentive to the sensory, embodied aspects of experience by evoking the context and the different sensory modalities as a way back into the experience - then refocusing on the manner (the how) of the experience rather than the content (the what). While this is very familiar territory to Buddhist meditators, what is interesting is that a similar approach is also found with Husserl's "phenomenological conversion." $\mathrm{He}$ writes: the conversion is achieved by diverting attention from the objects which appear to the consciousness towards the subjective modes of appearance of these objects (Husserl, 1913/1950, 1925/1962, in Petitmengin [59]). ${ }^{25}$ As Høffding and Martiny describe, Eriksonian open questions do not "presuppose more knowledge than they aim to gather, whereas closed questions introduce biases in their formulation and already suggest possible answers to the questions, as well as concepts useful for verbalizing them" [62].
}

move from lived experience, perhaps pre-reflective lived experience, to the reflective mode, there is a danger that the verbalization may interfere with the grasp of the experience. The interviewee must find his/her own words to express the experience, and this may be difficult or even impossible. These are some of the challenges of accessing pre-reflective experience with individuals who are not suffering anomalous experiences, and so in the context of a psychiatric assessment all of these challenges are escalated.

In the ground-breaking article on EASE (Examination of Anomalous Self-Experience, [58]), by psychiatrist Josef Parnas and his team, general guidelines are given for conducting an effective phenomenological interview. They stress that there are intrinsic difficulties in any interview process concerning anomalous experience for a number of reasons: the patient may never have communicated his experience to anyone previously; the experiences may be as described "fleeting" and "ineffable"; the patient may not have the verbal repertoire to articulate his experience; the experience may be pre-reflective or of a more general background sense of awareness, and thus indeterminate; the patient may also have an acute sense of humiliation to be having such experiences. Parnas et al. [58], also defend the special value of the use of metaphor in the context of the psychiatric interview in allowing pre-reflective experience to become reflectively accessible. Establishing an appropriate level of empathic resonance is also necessary. As Parnas et al. [58] write: "... it is mandatory to try and establish a neutral, yet caring rapport with the patient, and ideally to provide the patient with the possibility to act as a partner in a shared mutually interactive exploration" (p. 238), in other words, as we mentioned above, according the patient an important measure of epistemic responsibility alongside that of the psychiatrist.

Parnas and his colleagues demonstrate how this interview technique could be applied in the case of schizophrenia. Because they propose that schizophrenia is predominantly a self-disorder of the minimal self, the protocol they have devised reflects primarily these aspects. In terms of PTS, this protocol relates to the experiential aspects of self. In this regard, Parnas et al. [58] have identified five key aspects which are challenged in schizophrenia: cognition and stream of consciousness; self-awareness and presence (sense of self and immersion in the world); bodily experience; demarcation/transitivism (loss of permeability of self-world boundaries and self-other boundaries); and existential re-orientation (solipsistic or religious delusions, magical ideas, grandiosity). These are 
then mapped out with variations and indicators according to incidence and severity. It is easy to see that in this mapping, these aspects of experiential self-awareness are already in relation to other aspects of the larger self-pattern. Phenomenological interviews, based on the EASE scale, have demonstrated that disturbances in self-experience aggregate with schizophrenia, which makes it one of the most difficult psychiatric disorders to treat [154, 155].

\section{Conclusion: Benefits and Challenges of This Alternative Approach}

While we have only sketched here the basic outline of this approach, we hope this is sufficient to gain an appreciation of its potential in the situation of psychiatric assessment. The physician/interviewer will be able to track the evolving lived experience of the patient/ interviewee as it is expressed through and maps onto the self-pattern. So, rather than relying solely on fixed categories such as schizophrenic, autistic or paranoid, it would be possible to simply record or explicate in narrative form the specific self-pattern, the extent or incidence of difficulties with regard to the embodied, experiential, intersubjective, etc. aspects of the self-pattern and their relations.

As we have argued, when the categories are not reified, the categorical approach does have value as a tentative, revisable "field guide." Nonetheless, we propose that the alternative approach we have detailed above has a number of distinct and significant advantages over diagnostic categorization tools such as the DSM: first, because this alternative approach is describing symptoms according to the PTS and not trying to fit the symptoms into a particular psychiatric category, the issue of demarcation with regard to comorbidities becomes a nonproblem and possible misdiagnosis is avoided; second, the problem of symptom amplification is reduced if the interviewer is sufficiently aware of when the interviewee is shifting from embodied utterances to disembodied utterances - the latter indicating more likelihood of exaggeration and confabulation; ${ }^{26}$ third, because these aspects of self apply both to those who would otherwise be

\footnotetext{
${ }^{26}$ Disembodied utterances are discussed within micro-phenomenological interview training. The interviewer is trained to pick up on clues that indicate when someone is shifting from a direct pre-reflective 1st person mode into a 3 rd person reflective mode and could thus be introducing distortions/ inaccuracies into the narrative.
}

Towards a Phenomenology of

Self-Patterns categorized as "normal" and those who have anomalous experiences, the negative consequences of looping effects and stigmatization are potentially eliminated - mental health/illness can be measured along a continuum and is multidimensional; fourth, because of the continuum and multidimensionality measurements, investigations into the prodromal phases of mental distress would find such an approach useful; fifth, this approach is able to take account of changes, context, ${ }^{27}$ and all key modes of lived experience and is thereby able to track the evolution and devolution of the individual's experience; sixth (ideally), because access to services, insurance, and medication will not depend on fulfilling the criteria of a diagnostic category, there will no longer be conflict of interest for psychiatrists; ${ }^{28}$ seventh, it avoids the dehumanizing effects of the structured interview checklist and returns a significant measure of epistemic responsibility to the individual suffering anomalous experience, rather than deferring to solely neurobiological measures or the expertise of the psychiatrist; eighth, it gives recognition to the possibility that someone might have very good mental health while at the same time have a mental disorder; ninth, goals and aspirations according to each aspect of self can be negotiated between the interviewee/patient and the interviewer/psychiatrist so that evolution can be tracked and, importantly, the individual can regain a sense of power and purpose in their life; and finally, the assessment itself, building on and transforming the patient's self-narrative, engenders insight and through the positive effects of compassionate attention serves a therapeutic purpose.

There are, of course, some drawbacks. Extra training is required in the phenomenological interview method.

\footnotetext{
27 The situated aspects of the self-pattern involving, e.g., societal influences can be gauged and solutions sought in appropriate contexts of social practice. For example, in Iceland there was a problem with alcohol and drug abuse in young people and so the government sought a very practical and effective solution - substantial increases in investment in culture and sport and a curfew for young people. https://www.theatlantic.com/health/archive/2017/01/ teens-drugs-iceland/513668/

${ }^{28} \mathrm{We}$ are not advocating easier access to medications, but we are highlighting yet another problem with fixed diagnostics categories; there can be conflicts of interest for the psychiatrists who may legitimately deem a patient, who does not fulfill the precise criteria, to be in need of XYZ. In some cases, the psychiatrist may "adapt" the report of symptomatology so that the patient will get access to the appropriate treatment, service and/or insurance. We think PTS and phenomenological methodology will furnish a more finegrained assessment so that treatments will be more precisely targeted to include therapeutic interventions, reducing the predominant recourse to pharmaceutical interventions. PTS motivates a diversifying of treatments on offer to also include more personal and lifestyle investments such as CBT, narrative therapy, meditation, Qi Gong, art therapy, various movement therapies, etc. We would then expect there would be a need for insurance companies to adapt to the new kinds of demands, which is already happening.
} 
Furthermore, the interviewing process itself requires significant investments of time on the part of all parties. Nonetheless, given the scandalous direct and indirect costs that mental illness has already generated, such an investment would undoubtedly be cost-effective in the long-term.

\section{Statement of Ethics}

The authors have no ethical conflicts to disclose.

\section{Disclosure Statement}

The authors, Dr. Anya Daly and Prof. Shaun Gallagher, declare that to the best of their knowledge, they have no conflicts of interest in this publication.

\section{Author Contributions}

Both authors, Dr. Anya Daly and Prof. Shaun Gallagher, have made substantial contributions to the conception, analysis, drafting, revising, and approval of this article and have cited all publications drawn on accurately.

\section{References}

1 Scull A. The insanity of place/the place of insanity: essays on the history of psychiatry. New York, London: Routledge; 2006. https:// doi.org/10.4324/9780203087985.

2 Laing RD. The Divided Self: An Existential Study in Sanity and Madness. London: Penguin Books; 1990.

3 Szasz TS. The myth of mental illness. Am Psychol. 1960;15(2):113-8.

4 Foucault M. History of Madness. London: Routledge;2013.https://doi.org/10.4324/9780 203642603.

5 Bolton J. Further thoughts on the 4P Model. Philos Psychiatry Psychol. 2014;21(3):215-8.

6 Perring C. Are models irrelevant and incoherent? Philos Psychiatry Psychol. 2014;21(3): 199-201.

7 Porter R. Madness: A Brief History. Oxford: Oxford University Press; 2002.

8 Burstow B. A critique of posttraumatic stress disorder and the DSM. J Humanist Psychol. 2005;45(4):429-45.

9 O'Connor B. Mental disorder as a practical psychiatric kind. Philos Psychiatry Psychol. 2017;24(4):E1-13.

10 Caplan PJ. Psychiatry's bible, the DSM, is doing more harm than good. The Washington Post. 2012 Apr 27.

11 Duffy M, et al. A critical look at the DMS-IV J Individ Psychol. 2002;58(4):363-73.

12 Greenberg G. The book of woe: The DSM and the unmaking of psychiatry. London: Penguin; 2013.

13 Lafrance MN, McKenzie-Mohr S. The DSM and its lure of legitimacy. Fem Psychol. 2013; 23(1):119-40.

14 Lopez-Manoz F, Garcia-Garcia P, Saiz-Ruiz J, Mezzich JE, Rubio G, Vieta E, et al. A bibliometric study of the use of the classificationand diagnostic systems in psychiatry over the last 25 years. Psychopathology. 2008;41(4):21425.

15 Sharfstein SS. Big pharma and American psychiatry. J Nerv Ment Dis. 2008 Apr;196(4): 265-6.

16 Tartakovsky M. How the DSM Developed What You Might Not Know. Psych Central.
2011 [Retrieved on April 17, 2017]. Available from: https://psychcentral.com/blog/ archives/2011/07/02/how-the-dsm-developed-what-you-might-not-know/

17 Fulford KW, Broome M, Stanghellini G, Thornton T. Looking with both eyes open: fact and value in psychiatric diagnosis? World Psychiatry. 2005 Jun;4(2):78-86.

18 Andreasen NC. DSM and the death of phenomenology in america: an example of unintended consequences. Schizophr Bull. 2007 Jan;33(1):108-12.

19 Kendler KS. An historical framework for psychiatric nosology. Psychol Med. 2009 Dec; 39(12):1935-41.

20 Stein DJ. Dimensional or categorical: different classifications and measures of anxiety and depression. Medicographia. 2012;34: 270-5.

21 Frances AJ. Diagnosing the DSM. New York Times. 2012 May 11.

22 Frances AJ. DSM 5 is guide not bible-ignore its ten worst changes. Psychol Today. 2012 Dec 2.

23 Frances AJ. Saving normal: an insider's revolt against out-of-control psychiatric diagnosis, DSM-5, big pharma and the medicalization of ordinary life. Psychother Australia. 2013; 19(3):14.

24 Paris J. The Intelligent Clinician's Guide to the DSM-5. Oxford: Oxford University Press; 2013. https://doi.org/10.1093/med/97801997 38175.001 .0001$.

25 Stanghellini G. Philosophical Resources for the Psychiatric Interview. In: Fulford KWM. Davies M, Gipps R, Graham G, Sadler J, Stanghellini G, Thornton T, editors. The Oxford Handbook of Philosophy and Psychiatry. Oxford: Oxford University Press; 2013. p. 321-58.

26 Stanghellini G, Broome MR. Psychopathology as the basic science of psychiatry. Br J Psychiatry. 2014 Sep;205(3):169-70.

27 Craddock N, Mynors-Wallis L. Psychiatric diagnosis: impersonal, imperfect and important. Br J Psychiatry. 2014 Feb;204(2): 93-5.
28 Insel T: Director's Blog: Getting Serious About Mental Illnesses. Science. 2013. Retrieved 2017 Apr 15.

29 Insel T. Thomas Insel leaves the Googlespawned Verily for a start-up. In: Prochaska JO, Norcross JC, editors. Systems of Psychotherapy: A Transcendental Analysis. Oxford: Oxford University Press; 2018. p. 450

30 Kelly B. Chapter 2: Compassion, Cognition and the Illusion of Self: Buddhist Notes Towards a More Skilful Engagement with Diagnostic Classification Systems in Psychiatry. In: Shonin E, et al., editors. Mindfulness and Buddhist-Derived Approaches in Mental Health and Addiction. Basel, Switzerland: Springer International Publishing; 2016. https://doi.org/10.1007/978-3-319-22255$4 \_2$

31 Fuchs T. Ecology of the Brain. Oxford, New York: Oxford University Press; 2018. https:// doi.org/10.1093/med/9780199646 883.001 .0001

32 Jaspers K. Allgemeine psychopathologie: ein leitfaden für studierende, ärzte und psychologen. Heidelberg: Springer; 1913, 1948.

33 Jaspers K (Hoenig J, Hamilton MW, translators). General psychopathology. Manchester: Manchester University Press; 1963.

34 Sass LA, Parnas J. Explaining schizophrenia: the relevance of phenomenology. In: Chung MC, Fulford KWM, Graham G, editors. International perspectives in philosophy and psychiatry. Reconceiving Schizophrenia. New York, Oxford University Press; 2006. p. 6395.

35 Colombetti G. Some ideas for the integration of neurophenomenology and affective neuroscience. Constr Found. 2013;8(3): 288-97.

36 Kontos N. Can what's in your head be 'all in your head'?: Possibilities and problems of psychological symptom amplification (PSA). In: Moseley DD, Gala G, editors. Philosophy and Psychiatry: Problems, Intersections and New Perspectives. London, New York: Routledge; 2015 
37 Garson J. Commentary on Kontos: The hiddenness of symptom amplification - some historical observations. In: Moseley DD, Gala G, editors. Philosophy and Psychiatry: Problems, Intersections and New Perspectives. London, New York: Routledge; 2015.

38 Hacking I. The social construction of what? Cambridge (MA): Harvard University Press; 1999.

39 Hacking I. Between Michel Foucault and Erving Goffman: between discourse in the abstract and face-to-face interaction. Econ Soc. 2004;33(3):277-302.

40 Bentall R. Madness explained: why we must reject the Kraepelinian paradigm and replace it with a 'complaint-orientated' approach to understanding mental illness. Med Hypotheses. 2006;66(2):220-33.

41 Maser JD, Akiskal HS. Spectrum concepts in major mental disorders. Psychiatr Clin North Am. 2002 Dec;25(4):xi-xiii.

42 Krueger RF, Watson D, Barlow DH. Introduction to the special section: toward a dimensionally based taxonomy of psychopathology. J Abnorm Psychol. 2005 Nov;114(4):491-3.

43 Gallagher S. The cruel and unusual phenomenology of solitary confinement. Front Psychol. 2014 Jun;5:585.

44 Fulford KW, Sartorius N. The secret history of ICD and the hidden future of DSM. In Broome MR, Bortolotti L, editors. Psychiatry as cognitive neuroscience. International perspectives in philosophy and psychiatry series. Oxford: Oxford University Press; 2009. pp. 29-48.

45 Pilgrim D, Bentall R. The medicalisation of misery: A critical realist analysis of the concept of depression. J Ment Health. 1999;8(3): 261-74.

46 Pilgrim D. The survival of psychiatric diagnosis. Soc Sci Med. 2007 Aug;65(3):536-47.

47 Cosgrove L, Wheeler EE. Industry's colonization of psychiatry: ethical and practical implications of financial conflicts of interest in the DSM-5. Fem Psychol. 2013;23(1):93-106.

48 Parnas J, Gallagher S. Phenomenology and the interpretation of psychopathological experience. In: Kirmayer L, Lemelson R, Cummings C, editors. Revisioning Psychiatry Integrating Biological, Clinical and Cultural Perspectives. Cambridge: Cambridge University Press; 2015. pp. 65-80.

49 Decker HS. The making of DSM-III: A diagnostic manual's conquest of American psychiatry. Oxford: Oxford University Press; 2013.

50 Cuthbert BN, Insel TR. Toward the future of psychiatric diagnosis: the seven pillars of RDoC. BMC Med. 2013 May;11(1):126.

51 Parnas J, Drmed SC. Psychiatrists encounter patients who are real people inhabiting specific cultural and social contexts and who have, for one reason or another (and). In: Kendler KS, Parnas J, editors. Philosophical Issues in Psychiatry: Explanation, Phenomenology, and Nosology. Baltimore (Maryland): John Hopkins University Press; 2008. p. 387.
52 Perring C. Commentary on Kinghorn: evaluating traditions in psychiatry. In: Moseley DD, Gala G, editors. Philosophy and Psychiatry: Problems, Intersections and New Perspectives. London, New York: Routledge; 2015.

53 Marecek J, Hare-Mustin RT. Clinical psychology: The politics of madness. In: Fox D, Prilleltensky I, Austin S, editors. Critical psychology: An introduction. 2nd ed. Los Angeles: Sage; 2009. pp. 75-92.

54 Scharfstein SS. Big Pharma and American Psychiatry: The Good, the Bad, and the Ugly. Psychiatric News. American Psychiatry Association. 2005;40(16):3

55 Jablensky A. Karl Jaspers: psychiatrist, philosopher, humanist. Schizophr Bull. 2013 Mar; 39(2):239-41.

56 Varela FJ. Neurophenomenology: A methodological remedy for the hard problem. J Conscious Stud. 1996;3(4):330-49.

57 Vermersch P: L'explicitation de l'action. Cahiers Ling Soc. 1996;3:113-120.

58 Parnas J, Møller P, Kircher T, Thalbitzer J, Jansson L, Handest P, et al. EASE: examination of anomalous self-experience. Psychopathology. 2005 Sep-Oct;38(5):236-58.

59 Petitmengin C. Describing one's subjective experience in the second person: an interview method for the science of consciousness. Phenomenol Cogn Sci. 2006;5(3-4):229-69.

60 Petitmengin C, Bitbol M. Let's Trust the (skilled) Subject! A Reply to Froese, Gould and Seth. J Conscious Stud. 2011; 18(2): $90-7$

61 Olivares FA, Vargas E, Fuentes C, MartínezPernía D, Canales-Johnson A. Neurophenomenology revisited: second-person methods for the study of human consciousness. Front Psychol. 2015 May;6:673.

62 Høffding S, Martiny K. Framing a phenomenological interview: what, why and how. Phenomenol Cogn Sci. 2016;15(4):539-64.

63 Merleau-Ponty M. The Phenomenology of Perception. Translated by Smith C. London: Routledge; 1962, 2006.

64 Merleau-Ponty M. The Phenomenology of Perception. Translated by Lades DA. Abingdon: Routledge; 2012.

65 Carel H. Living in the present: Illness, phenomenology, and wellbeing. In: Jackson $\mathrm{M}$, editor. Routledge History of Disease. London: Routledge; 2017. pp. 581-99.

66 Parnas J, Handest P. Phenomenology of anomalous self-experience in early schizophrenia. Compr Psychiatry. 2003 Mar-Apr; 44(2):121-34

67 Gallagher S, Varga S. Social cognition and psychopathology: a critical overview. World Psychiatry. $2015 \mathrm{Feb} ; 14(1): 5-14$

68 Keil G, Keuk L, Hauswald R. Vagueness in Psychiatry. New York: Oxford University Press; 2017.

69 Dinos S, Stevens S, Serfaty M, Weich S, King M. Stigma: the feelings and experiences of 46 people with mental illness. Qualitative study. Br J Psychiatry. 2004 Feb;184(2):176-81.
70 Read J, Haslam N, Sayce L, Davies E. Prejudice and schizophrenia: a review of the 'mental illness is an illness like any other' approach. Acta Psychiatr Scand. 2006 Nov;114(5):30318.

71 Metzinger T. The ego tunnel: The science of the mind and the myth of the self. New York: Basic Books; 2010

72 Northoff G, Bermpohl F. Cortical midline structures and the self. Trends Cogn Sci. 2004 Mar;8(3):102-7.

73 Northoff G, Heinzel A, de Greck M, Bermpohl F, Dobrowolny H, Panksepp J. Self-referential processing in our brain - a meta-analysis of imaging studies on the self. Neuroimage. 2006 May:31(1):440-57.

74 Northoff G, Panksepp J. The trans-species concept of self and the subcortical-cortical midline system. Trends Cogn Sci. 2008 Jul; 12(7):259-64.

75 Legrand D, Ruby P. What is self-specific? Theoretical investigation and critical review of neuroimaging results. Psychol Rev. 2009 Jan;116(1):252-82.

76 Vogelely K, Gallagher S. The Self in the Brain In: Gallagher S, editor. The Oxford Handbook of the Self. Oxford: Oxford University Press; 2011. pp. 111-36.

77 Zahavi D. Subjectivity and Selfhood. Cambridge (MA): MIT Press; 2005. https://doi. org/10.7551/mitpress/6541.001.0001.

78 Gillihan SJ, Farah MJ. Is self special? A critical review of evidence from experimental psychology and cognitive neuroscience. Psychol Bull. 2005a Jan;131(1):76-97.

79 Gillihan SJ, Farah MJ. The Cognitive Neuroscience of the Self: Insights from Functional Neuroimaging of the Normal Brain. In: Feinberg TE, Keenan JP, editors. The Lost Self; Pathologies of the Brain and Identity. Oxford, New York: Oxford University Press; 2005b. https://doi.org/10.1093/acprof:o so/9780195173413.003.0003.

80 Fingelkurts AA, Fingelkurts AA. Three-dimensional components of selfhood in treatment-naive patients with major depressive disorder: A resting-state qEEG imaging study. Neuropsychologia. 2017 May;99:30-6.

81 Gallagher S. A pattern theory of self. Front Hum Neurosci. 2013a Aug; 7:443.

82 Izard CE, Bartlett ES, Marshall AG. Patterns of Emotions. Washington: Academic Press; 1972.

83 Strawson G. The self and the SESMET. J Conscious Stud. 1999;6:99-135.

84 Gallagher S, Daly A. Dynamical relations in the self-pattern. Front Psychol. 2018 May;9: 664

85 Gallagher S, Zahavi D. The Phenomenological Mind. London, New York: Routledge; 2012.

86 Newen A, Welpinghus A, Juckel G. Emotion recognition as pattern recognition: the relevance of perception. Mind Lang. 2015;30(2): 187-208.

87 Neisser U. Five Kinds of Self-Knowledge. Philos Psychol. 1988;1(1):35-59. 
88 Sartre JP. Being and Nothingness: And Essay on Phenomenological Ontology. Paris, Gallimard 1943. Trans (New York): Washington Square Press; 1956.

89 Mead GH. The Social Self. J Philos 1913;10: 374-380

90 Shoemaker S. Self-Reference and SelfAwareness. J Philos. 1968;65(19):555-67.

91 Schechtmann M. The Narrative Self. In: Gallagher S, editor. The Oxford Handbook of the Self. Oxford: Oxford University Press; 2011.

92 James W. The Principles of Psychology. 1st published Henry Holt and Co., 1890. New York: Dover Publications Inc.; 1950.

93 Ataria Y, Gallagher S. Somatic apathy: body disownership in the context of torture. J Phenomenol Psychol. 2015;46(1):105-22.

94 Dennett D. Real patterns. J Philos. 1991; 88(1):27-51.

95 Haugeland J. Having Thought: Essays in the Metaphysics of Mind. Cambridge (MA): Harvard University Press; 1998.

96 Parnas J, Sass LA, Zahavi D. Rediscovering psychopathology: the epistemology and phenomenology of the psychiatric object. Schizophr Bull. 2013 Mar;39(2):270-7.

97 Nordgaard J, Sass LA, Parnas J. The psychiatric interview: validity, structure, and subjectivity. Eur Arch Psychiatry Clin Neurosci. 2013 Jun;263(4):353-64.

98 Fuchs T. Corporealized and disembodied minds: a phenomenological view of the body in melancholia and schizophrenia. Philos Psychiatry Psychol. 2005;12(2):95-107.

99 Fuchs T, Schlimme JE. Embodiment and psychopathology: a phenomenological perspective. Curr Opin Psychiatry. 2009 Nov; 22(6):570-5.

100 Gallagher S. How the body shapes the mind. Oxford: Oxford University Press; 2005. https://doi.org/10.1093/0199271941.001.00 01.

101 de Haan S, Fuchs T. The ghost in the machine: disembodiment in schizophreniatwo case studies. Psychopathology. 2010; 43(5):327-33.

102 Ratcliffe M. Experiences of depression: A study in phenomenology. Oxford: Oxford University Press; 2014.

103 Trigg D. Topophobia: A phenomenology of anxiety. London: Bloomsbury Publishing; 2016.

104 Gallagher S. Patterns of the Self in Therapeutic Contexts. Presented at: 15th European Congress of Body Psychotherapy, The Embodied Self in a Dis-Embodied Society. 2016 Oct 13-16; Athens.

105 Styron W. Darkness visible: A memoir of madness. New York: Random House; 1990.

106 Foster Wallace D. The Depressed Person. Harper's Magazine. 1998 Jan.

107 Solomon A. The Noonday Demon: An Atlas of Depression. New York: Scribner; 2001.

108 O'Brien S. The Family Silver: A Memoir of Depression and Inheritance. Chicago: University of Chicago Press; 2004.
109 Paskaleva A. A phenomenological assessment of depression narratives. Osnabrück: Publications of the Institute of Cognitive Science; 2011.

110 Slaby J, Stephan A. Affective intentionality and self-consciousness. Conscious Cogn. 2008 Jun;17(2):506-13.

111 Bovet P, Parnas J. Schizophrenic delusions: a phenomenological approach. Schizophr Bull. 1993;19(3):579-97.

112 Phillips J. Schizophrenia and the narrative self. In: David AS, Kircher T, editors. The Self in Neuroscience and Psychiatry. Cambridge: Cambridge University Press; 2003. pp. 319-35.

113 Gallagher S, Cole J. Dissociation in self-narrative. Conscious Cogn. 2011 Mar;20(1): 149-55.

114 Stanghellini G, Ballerini M, Presenza S, Mancini M, Raballo A, Blasi S, et al. Psychopathology of Lived Time: Abnormal Time Experience in Persons With Schizophrenia. Schizophr Bull. 2016 Jan;42(1):45-55.

115 Stirman SW, Pennebaker JW. Word use in the poetry of suicidal and nonsuicidal poets. Psychosom Med. 2001 Jul-Aug;63(4):51722.

116 Pennebaker JW, Mehl MR, Niederhoffer KG. Psychological aspects of natural language. use: our words, our selves. Annu Rev Psychol. 2003;54(1):547-77.

117 Ratcliffe M. Varieties of temporal experience in depression. J Med Philos 2012;37(2):114138.

118 Bruner J. Acts of Meaning. Cambridge (MA): Harvard University Press; 1990.

119 Flint J, Kendler KS. The genetics of major depression. Neuron. 2014 Feb;81(3):484503.

120 Opel N, Redlich R, Zwanzger P, Grotegerd D, Arolt V, Heindel W, et al. Hippocampal atrophy in major depression: a function of childhood maltreatment rather than diagnosis? Neuropsychopharmacology. 2014 Nov; 39(12):2723-31.

121 Barton DA, Esler MD, Dawood T, Lambert EA, Haikerwal D, Brenchley C, et al. Elevated brain serotonin turnover in patients with depression: effect of genotype and therapy. Arch Gen Psychiatry. 2008 Jan;65(1):38-46.

122 Hutto D, Gallagher S. Re-authoring narrative therapy: opening the way for future developments. Philos Psychiatry Psychol. 2017;24(2):157-67.

123 Cole J. Gallagher. S: Narrative and Clinical Neuroscience: Can phenomenologically informed approaches and empirical work cross-fertilize? In: Whitehead A, Woods A, editors. The Edinburgh Companion to the Critical Medical Humanities. Edinburgh: Edinburgh University Press; 2016.

124 Gallagher S. Pathologies in narrative structure. In: Hutto D, editor. Narrative and Understanding Persons. Cambridge: Cambridge University Press; 2007. p. 203-224.

125 Gallagher S, Hutto D: Understanding others through primary interaction and narrative practice. In: Zlatev J, Racine TP, Sinha C, Itkonen E, editors. The shared mind: Perspectives on intersubjectivity. Amsterdam: John Benjamins; 2008. p. 17-38.

126 Strawson G. Against narrativity. Ratio. 2004 17(4):428-52.

127 White M, Epston D. Narrative means to therapeutic ends. New York: WW. Norton; 1990.

128 White M. Narrative practice and exotic lives: Resurrecting diversity in every day life. Adelaide: Dulwich Centre Publications; 2004.

129 Biegler P. The ethical treatment of depression: autonomy through psychotherapy. Cambridge (MA): MIT Press; 2011. https://doi.org/10.7551/mitpress/978026 2015493.001.0001.

130 Gallagher S, Hutto D: Embodied and narrative practices in the clinical context [working paper]. Roundtable on Embodied Narrative Practices. Hatfield: University of Hertfordshire; 2012.

131 Øberg GK, Normann B, Gallagher S. Embodied-enactive clinical reasoning in physical therapy. Physiother Theory Pract. 2015 May;31(4):244-52.

132 Gallagher S, Payne H: The role of embodiment and intersubjectivity in clinical reasoning. Body Mov Dance Psychother. 2015 10(1):68-78

133 Dings R, de Bruin L. Situating the self: understanding the effects of deep brain stimulation. Phenomenol Cogn Sci. 2016;15(2): $151-65$.

134 de Haan S, Rietveld E, Stokhof M, Denys D. The phenomenology of deep brain stimulation-induced changes in OCD: an enactive affordance-based model. Front Hum Neurosci. 2013 Oct; $7: 653$

135 Lipsman N, Glannon W. Brain, mind and machine: what are the implications of deep brain stimulation for perceptions of personal identity, agency and free will? Bioethics. 2013 Nov;27(9):465-70.

136 Belle D. Poverty, inequality, and discrimination as sources of depression among US women. Psychol Women Q. 2003;27(2): 101-13.

137 Broome M. Suffering and Eternal Recurrence of the Same: the Neuroscience, psychopathology and philosophy of time. Philos Psychiatry Psychol. 2005; 12(3):187-94.

138 Kelly BD. Hearing Voices: Lessons from the History of Psychiatry in Ireland. Ir Med J. 2017a Mar;110(3):537-537.

139 Kelly BD: Love as delusion, delusions of love: erotomania, narcissism and shame. Med Humanit. 2018 Mar;44(1):15-19.

140 Kirk SA, Gomory T, Cohen D. Mad Science: Psychiatric coercion, diagnosis, and drugs. Transaction Publishers, 2013. London, New York: Routledge; 2017. https://doi.org/ 10.4324/9780203786765.

141 Manning M. Undercurrents: A Life Beneath the Surface. San Francisco: Harper; 1994. 
142 Radden J. Moody Minds Distempered: Essays on Melancholy and Depression (an edited collection of previously published writing). Oxford: Oxford University Press; 2009.

143 Stanghellini G, Ballerini M, Presenza S, Mancini M, Northoff G, Cutting J. Abnormal Time Experiences in Major Depression: An Empirical Qualitative Study. Psychopathology. 2017;50(2):125-40.

144 Westerbeck J, Mutsaers K. Depression Narratives: How the Self Became a Problem. Lit Med. 2008;27(1):25-53.

145 Wolpert L. Malignant Sadness: The Anatomy of Depression. New York: Free Press; 1999.

146 Wurtzel E. Prozac Nation: Young and Depressed in America. New York: Riverhead; 1995.

147 Vermersch P. Explicitation et Phénoménologie: Vers une psychophénoménologie. Paris: Presses Universitaires de France; 2012.
148 Petitmengin C. Review of 'Explicitation et phénoménologie' by Pierre Vermersch. J Conscious Stud. 2014;21(11-12):196-201.

149 Lutz A, Lachaux JP, Martinerie J, Varela FJ. Guiding the study of brain dynamics by using first-person data: synchrony patterns correlate with ongoing conscious states during a simple visual task. Proc Natl Acad Sci USA. 2002 Feb;99(3):1586-91.

150 Varela FJ, Shear J. The View from Within: First Person Approaches to the Study of Consciousness. Thorverton (UK). Bowling Green, USA: Imprint Academic; 1999.

151 Nyquist Potter N. Empathic Foundations of Clinical Knowledge; in Fulford KWM, Davies M, Gipps R, Graham G, Sadler J, Stanghellini G, Thornton T, editors. Oxford: The Oxford Handbook of Philosophy and Psychiatry; 2013. p. 293-306.

152 Gallagher S. Intersubjectivity and Psychopathology. In: Fulford KW, Davies M,
Gipps R, Graham G, Sadler J, Stanghellini G, et al., editors. Oxford: The Oxford Handbook of Philosophy and Psychiatry; 2013. p. 258-74.

153 Dreyfus HL (Wrathall MA, editor). Skillful Coping: Essays on the phenomenology of everyday perception and action. Oxford: Oxford University Press; 2014. https://doi. org/10.1093/acprof:oso/97801996 54703.001.0001.

154 Parnas J, Henriksen MG. Disordered self in the schizophrenia spectrum: a clinical and research perspective. Harv Rev Psychiatry. 2014 Sep-Oct;22(5):251-65.

155 Norgaard J, Henriksen M. Phenomenological Psychopathology and Quantitative Research. In: Stanghellini G, Raballo A, Broome M, Fernandez AV, Fusar-Poli P, Rosfort R, editors. The Oxford Handbook of Phenomenological Psychopathology. Oxford: Oxford University Press; 2018. 